\title{
Filtering Hoax Menggunakan Naive Bayes Classifier
}

\author{
P.D Utami, Risna Sari \\ Program Studi Teknik Informatika \\ Politeknik Negeri Jakarta \\ Depok, Indonesia \\ putri.dinda.tik14@mhsw.pnj.ac.id,risna.sari@tik.pnj.ac.id
}

Diterima: 11 April 2018. Disetujui: 24 April 2018. Dipublikasikan: Mei 2018

\begin{abstract}
Abstrak - Forum merupakan salah satu tempat berinteraksi dan berpartisipasi dalam komunitas dunia maya yang memiliki minat yang sama. Forum mempunyai topik yang bermacam-macam, salah satunya adalah topik tentang kecantikan. Isi dari forum kecantikan adalah tentang tips dan trik tentang kecantikan. Namun, banyaknya komentar serta opini-opini dari pengguna lain membuat sulitnya mencari fakta dan hoax pada komentar forum. Laporan ini, menjelaskan tentang pendekatan algoritma naïve bayes classifier untuk mendeteksi hoax pada komentar forum Female Daily. Tujuan dari penelitian ini adalah untuk mempermudah pengguna dalam mendeteksi hoax pada komentar thread forum. Penelitian ini memuat rancangan, membangun implementasi sistem dan melakukan tahapan data testing. Data training pada sistem ini didapat dari artikel pada website Female Daily. Dilakukan proses text preprocessing terlebih dahulu pada komentar sebelum data dihitung jumlah probabilitasnya dengan menggunakan algoritma naïve bayes classifier. Pada tahap testing didapatkan hasil akurasi sebanyak $88 \%$ dengan data testing sebanyak 50 komentar.
\end{abstract}

Kata Kunci: filtering, hoax, naïve bayes, classifier.

\section{PENDAHULUAN}

Pasal 27 sampai dengan Pasal 37 UU Nomor 1 Tahun 2008 tentang ITE. No.11/2008 Informasi dan Transaksi Elektronik (ITE), yang bunyinya "siapa pun masyarakat yang membuat konten negatif, ujaran kebencian, hoax dan menyebarkannya bisa dikenakan hukuman tahanan dan denda". Ke depannya diharapkan Indonesia bisa memiliki mesin hoaxbuster dengan database lengkap yang secara otomatis meredam informasi dan penyebaran hoax. Diakuinya saat ini, kapasitas pemerintah untuk mengawasi isu yang berisi hoax masih sangat terbatas. Dari konten yang selama ini dipublikasikan oleh Female Daily Network, artikel kecantikan terbukti yang paling banyak dibaca.

Terdapat 7,5 juta page view per bulan, 18,000 forum threads, 4,5 juta forum posts, serta 450 member baru per-hari di tahun 2015 lalu, dan akan terus bertambah. Forum mempunyai thread dan terdapat komentar serta opini-opini membuat pengguna seringkali kesulitan untuk menemukan informasi yang sesuai atau informasi yang benar. Komentar atau review pada suatu produk pada forum Female Daily perlu untuk disaring terlebih dahulu untuk mengetahui adanya komentar yang mengandung hoax, yang selama ini dilakukan secara manual oleh admin [1].

Permasalahan tersebut dapat diselesaikan dengan adanya sistem yang dapat mem-filtering hoax yang dapat membantu admin dalam memfilter komentar pada forum. Sistem akan menampilkan hasil klasifikasi dari komentar. Hasil klasifikasi tersebut dapat berupa fakta, netral ataupun hoax, tergantung dari jumlah probabilitas pada data training, namun tetap sesuai dengan kriteria yang berlaku. Sehingga, sistem ini diharapkan mempermudah pekerjaan admin serta mempermudah pengguna untuk memilih komentar yang ada. Fitur filtering hoax dibuat dengan menggunakan algoritma Naïve Bayes Classifier yang sebelumnya dilakukan oleh Granik \& Mesyura [2], dengan judul Fake News Detection Using Naïve Bayes Classifier menggunakan algoritma Naïve Bayes Classifier untuk mendeteksi berita hoax dengan menggunakan API dari sosial media Facebook dengan tingkat keakuratan sebesar $74 \%$. Fitur filtering hoax dapat membantu mengklasifikasikan komentar pada thread. Maka dari itu, fitur filtering hoax dapat membantu admin dan member untuk mengklasifikasikan komentar.

\section{TINJAUAN PUSTAKA}

\section{A. Text Preprocessing}

Text preprocessing adalah untuk membangun satu set fitur yang relevan dari text pada dokumen. Semua set fitur dipilih untuk koleksi dokumen yang disebut repsentional model. Setiap dokumen diwakili oleh nilai numeric vector. Tujuan dari text preprocessing adalah untuk mengekstrak vector fitur berkualitas tinggi untuk 
setiap dokumen, sehingga values yang diambil adalah values yang bernilai tinggi atau penting. [3] Berikut di bawah ini adalah proses tahapan dari text preprocessing yang akan digunakan untuk membangun sistem ini.

1) Case Folding.

Case Folding adalah konversi teks menjadi suatu bentuk standar, biasanya huruf kecil atau disebut juga lowercase. Sebagai contoh, user menginput "KOMPUTER", "Komputer", atau "KomPuter", maka fungsi dari case folding adalah untuk memberikan hasil yang sama yaitu "komputer". Case folding adalah mengubah semua huruf di dalam dokumen menjadi huruf kecil. Hanya huruf 'a-z' yang diterima. Karakter selain huruf akan dihilangkan dan dianggap delimiter.

2) Parsing/Tokenizing.

Tokenizing adalah pemotongan string input berdasarkan tiap kata yang menyusunnya dan memecah sekumpulan karakter dalam suatu teks ke dalam suatu kata. Pemisah dapat berupa spasi, enter, dan tabulasi dianggap sebagai pemisah kata. Di bawah ini adalah contoh tokenizing.

3) Stopword.

Berhenti pada kata-kata yang sudah diprediksi dari bahasa, yaitu kata-kata yang tidak memiliki artian atau informasi yang penting. Contoh stopword dalam bahasa Indonesia adalah yang, di, ke, adalah, akhir, apabila, dan lain-lain. Kata-kata tersebut akan dilewati begitu saja oleh sistem sehingga, hanya kata yang memiliki makna penting yang akan diambil.

\section{B. Naive Bayes Classifier}

Berbagai penelitian menggunakan Algoritma Naïve Bayes Classifier (NBC) sebagai metode pengklasifikasian teks. Salah kasus yang menggunakan algoritma ini untuk pengklasifikasian teks yaitu oleh [3]. Pada penelitian tersebut mengungkapkan bahwa penggunaan metode NBC dapat digunakan untuk pengklasifikasian otomatis terhadap data forum dengan tingkat akurasi klasifikasi sebesar $73 \%$ dengan menggunakan pengukuran efektifitas Confusion Matrix. Namun kekurangan pada penelitian ini masih perlu menambahkan fitur khusus dalam tokenisasi kalimat sehingga dapat menghasilkan klasifikasi dengan akurasi yang lebih tinggi. Sedangkan pada penelitian yang dilakukan oleh Trinanda [4] untuk kasus dokumen pada aplikasi perpustakaan algoritma Naïve Bayes Classifier (NBC) dapat diimplementasikan pada aplikasi tersebut untuk pengklasifikasian dokumen. Kekuranganya adalah butuh penyempurnaan algoritma serta penambahan data learning yang lebih banyak agar mendapatkan hasil yang lebih baik. Pada penelitian sebelumnya tentang "Klasifikasi Artikel Berita Secara Otomatis
Menggunakan Metode Naïve Bayes yang dimodifikasi" menghasilkan peningkatan rata-rata sebesar $2,3 \%$ dengan cara meningkatkan data training yang digunakan sebagai pembelajaran pada penelitian yang dilakukan oleh Mahmudy dan Widodo [5].

Rumus untuk Algoritma Naive Bayes Classifier [6]:

$$
\begin{gathered}
P(C \mid d)=P(C) \prod \prod_{i=1}^{n} P(W i \mid C) \\
P(W i \mid C)=\frac{\operatorname{count}(w i . c)+1}{\operatorname{count}(c)+|V|}
\end{gathered}
$$

Keterangan:

$$
\begin{array}{ll}
C & : \text { Class } \\
\mathrm{D} & : \text { Dokumen } \\
W i & : \text { Kata ke-i }
\end{array}
$$

$(W i \mid C) \quad$ : Jumlah kata wi dalam $\mathrm{C}$

Count (C) : Jumlah kata di class C

$|\mathrm{V}| \quad$ : Jumlah Vocabulary (Semua kata)

\section{Confusion Matrix}

Confusion matrix adalah sebuah tabel yang menyatakan jumlah data uji yang benar diklasifikasikan dan jumlah data uji yang salah diklasifikasikan [3]. Contoh confusion matrix untuk klasifikasi biner ditunjukkan pada Tabel 1.

TABEL 1. CONFUSION MATRIX

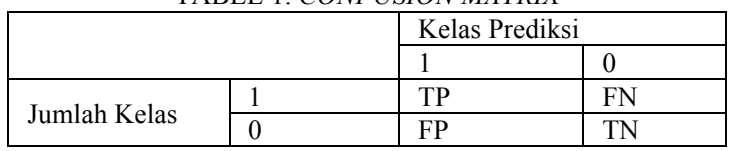

Berikut di bawah ini adalah keterangan dari Tabel 1:

True Positive (TP), yaitu jumlah dokumen dari kelas 1 yang benar dan diklasifikan sebagai kelas 1 . True Negative (TN), yaitu jumlah dokumen dari kelas 0 yang benar diklasifikasikan sebagai kelas 0 . False Positive (FP), yaitu jumlah dokumen dari kelas 0 yang salah diklasifikasikan sebagai kelas 1 . False Negative (FN) yaitu jumlah dokumen dari kelas 1 yang salah diklasifikasikan sebagai kelas 0 .

$$
\text { Akurasi }=\frac{T P+T N}{T P+F N+F P+T N} \times 100 \%
$$


D. Implementation Filtering Hoax

1) Alur Kerja Sistem

Gambar 1 adalah alur kerja Algoritma Naive Bayes Clasiffier untuk filtering hoax.

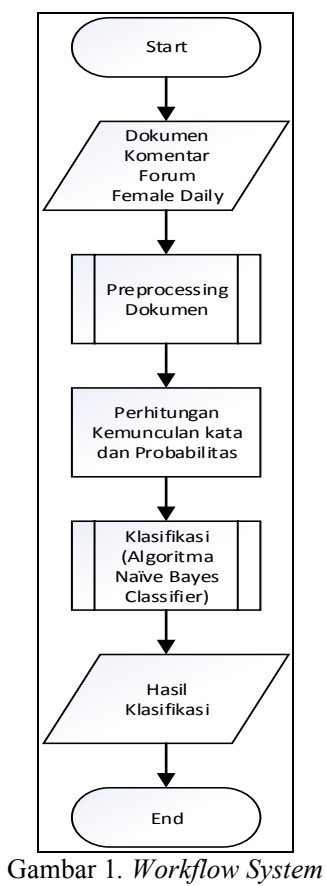

2) Text Preprocessing

Di bawah ini adalah sintaks dari tahapan text preprocessing.

- $\quad$ Case Folding.

\$sentence = preg_replace("/[^a-zA-Z 0-9]+/", "', \$sentence $=$ strtolower $($ Sentence $)$;

- Tokenizing.

\$sentence $=$ preg_replace ("/[^a-zA-Z 09]+/", " ",

\$sentence = strtolower (\$sentence);

- $\quad$ Stopword

\$stopWords = array ();

\$words $=$ DB: :table('stopwords') -

>select ('word sw')->get ();

foreach (\$words as \$word) \{

array push (\$stopWords, \$word->word_sw);

- $\quad$ Naive Bayes Classifier

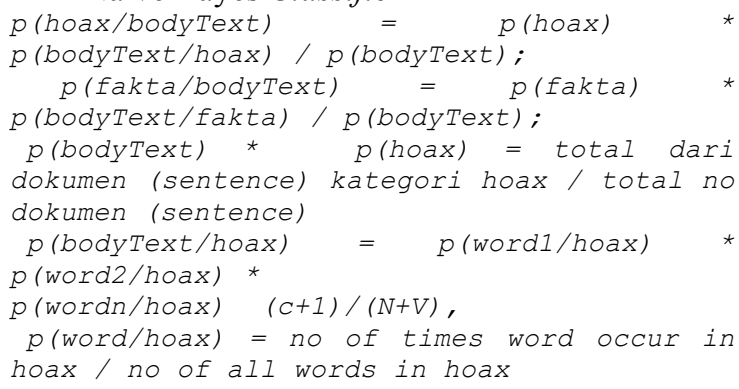

Tabel 2. Kalimat dan Hasil Indexing

\begin{tabular}{|c|c|c|c|c|c|c|}
\hline \multirow[b]{2}{*}{ Kata } & \multirow[b]{2}{*}{$\begin{array}{l}\text { Tokeni } \\
\text { sasi }\end{array}$} & \multicolumn{2}{|c|}{ Indexing } & \multicolumn{3}{|c|}{ Weighting } \\
\hline & & $\begin{array}{l}\text { clas } \\
\end{array}$ & $\begin{array}{l}\text { cou } \\
n t\end{array}$ & fakta & netral & hoax \\
\hline Yang & yang & $\begin{array}{l}\text { dele } \\
\text { te }\end{array}$ & $\begin{array}{l}N U \\
L L\end{array}$ & $N U L L$ & $N U L L$ & NULL \\
\hline $\begin{array}{l}\text { terbuk } \\
\text { ti }\end{array}$ & $\begin{array}{l}\text { terbukt } \\
\mathrm{i}\end{array}$ & $\begin{array}{l}\text { Hoa } \\
x \\
\end{array}$ & 1 & $\begin{array}{l}1 x(0+1 \\
)=1\end{array}$ & $\begin{array}{l}1 x(0+1 \\
)=1\end{array}$ & $\begin{array}{l}1 \times(1+1 \\
)=2\end{array}$ \\
\hline adalah & adalah & $\begin{array}{l}\text { Del } \\
\text { ete }\end{array}$ & $\begin{array}{l}N U \\
L L\end{array}$ & $N U L L$ & $N U L L$ & NULL \\
\hline $\begin{array}{l}\text { korela } \\
\text { si }\end{array}$ & $\begin{array}{l}\text { korelas } \\
\mathrm{i}\end{array}$ & $\begin{array}{l}N U \\
L L \\
\end{array}$ & $\begin{array}{l}N U \\
L L\end{array}$ & $N U L L$ & $N U L L$ & NULL \\
\hline dan & dan & $\begin{array}{l}\text { dele } \\
\text { te }\end{array}$ & $\begin{array}{l}N U \\
L L \\
\end{array}$ & $N U L L$ & $N U L L$ & $N U L L$ \\
\hline bukan & bukan & $\begin{array}{l}N U \\
L L \\
\end{array}$ & $\begin{array}{l}N U \\
L L\end{array}$ & $N U L L$ & $N U L L$ & NULL \\
\hline $\begin{array}{l}\text { kausal } \\
\text { itas }\end{array}$ & $\begin{array}{l}\text { kausali } \\
\text { tas }\end{array}$ & $\begin{array}{l}N U \\
L L\end{array}$ & $\begin{array}{l}N U \\
L L\end{array}$ & $N U L L$ & $N U L L$ & NULL \\
\hline $\begin{array}{l}\text { Selam } \\
\mathrm{a}\end{array}$ & selama & $\begin{array}{l}N U \\
L L\end{array}$ & $\begin{array}{l}N U \\
L L\end{array}$ & $N U L L$ & $N U L L$ & NULL \\
\hline ini & ini & $\begin{array}{l}N U \\
L L \\
\end{array}$ & $\begin{array}{l}N U \\
L L \\
\end{array}$ & $N U L L$ & $N U L L$ & NULL \\
\hline $\begin{array}{l}\text { marke } \\
\text { ting }\end{array}$ & $\begin{array}{l}\text { market } \\
\text { ing }\end{array}$ & $\begin{array}{l}N U \\
L L\end{array}$ & $\begin{array}{l}N U \\
L L\end{array}$ & $N U L L$ & $N U L L$ & NULL \\
\hline atau & atau & $\begin{array}{l}\text { Del } \\
\text { ete }\end{array}$ & $\begin{array}{l}N U \\
L L\end{array}$ & $N U L L$ & $N U L L$ & $N U L L$ \\
\hline artikel & artikel & $\begin{array}{l}N U \\
L L\end{array}$ & $\begin{array}{l}N U \\
L L\end{array}$ & $N U L L$ & $N U L L$ & NULL \\
\hline $\begin{array}{l}\text { umum } \\
\text { nya }\end{array}$ & $\begin{array}{l}\text { umum } \\
\text { nya }\end{array}$ & $\begin{array}{l}N U \\
L L \\
\end{array}$ & $\begin{array}{l}N U \\
L L \\
\end{array}$ & $N U L L$ & $N U L L$ & NULL \\
\hline bahas & bahas & $\begin{array}{l}N U \\
L L \\
\end{array}$ & $\begin{array}{l}N U \\
L L \\
\end{array}$ & $N U L L$ & $N U L L$ & NULL \\
\hline $\begin{array}{l}\text { parabe } \\
\mathrm{n}\end{array}$ & $\begin{array}{l}\text { parabe } \\
\mathrm{n}\end{array}$ & $\begin{array}{l}\text { hoa } \\
x\end{array}$ & 1 & $\begin{array}{l}1 \times(0+1 \\
)=1\end{array}$ & $\begin{array}{l}1 x(0+1 \\
)=1\end{array}$ & $\begin{array}{l}2 \times(1+1 \\
)=4\end{array}$ \\
\hline diduga & diduga & $\begin{array}{l}N U \\
L L\end{array}$ & $\begin{array}{l}N U \\
L L\end{array}$ & $N U L L$ & $N U L L$ & $N U L L$ \\
\hline $\begin{array}{l}\text { penye } \\
\text { bab }\end{array}$ & $\begin{array}{l}\text { penyeb } \\
\mathrm{ab}\end{array}$ & $\begin{array}{l}N U \\
L L\end{array}$ & $\begin{array}{l}N U \\
L L\end{array}$ & $N U L L$ & $N U L L$ & $N U L L$ \\
\hline kanker & kanker & $\begin{array}{l}\text { hoa } \\
x\end{array}$ & 1 & $\begin{array}{l}1 \times(0+1 \\
)=1\end{array}$ & $\begin{array}{l}1 \times(0+1 \\
)=1\end{array}$ & $\begin{array}{l}3 \times(1+1 \\
)=6\end{array}$ \\
\hline \multicolumn{4}{|l|}{ Hasil } & $\begin{array}{l}1 / 0+18 \\
=0,05\end{array}$ & $\begin{array}{l}1 / 0+18 \\
=0,05\end{array}$ & $\begin{array}{l}6 / 3+18 \\
=0,28\end{array}$ \\
\hline Result & & & & Hoax & & \\
\hline
\end{tabular}

\section{Information:}

Delete class : Word deleted when text preprocessing

Null Class : Words that are not counted in any class

Tabel 2 menunjukkan hasil setelah mengalami proses indexing.

\section{HASIL DAN ANALISA}

\section{A. Analisis Jumlah Data Training Tidak Seimbang}

Data training awalnya adalah sebanyak 25 fakta dan 25 hoax. Kemudian, ditambahkan 1 data training fakta, sehingga data training adalah 26 fakta dan 25 hoax. Berikut hasilnya pada Gambar 2 


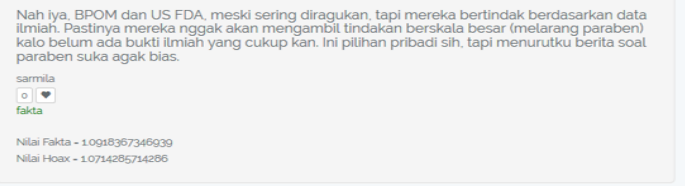

Gambar 2. Hasil Data Training Fakta Lebih Banyak

Hasil pada sistem adalah fakta sebanyak 1,091836734639 dan hoax sebanyak 1, 0714285714286, dengan hasil klasifikasi fakta dan sudah sesuai. Kemudian ditambahkan 1 data training kelas hoax. Sehingga data training menjadi 25 fakta dan 26 hoax. Berikut pada Gambar 3 menunjukkan hasil yang didapatkan.

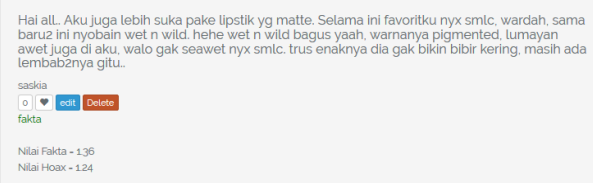

Gambar 3. Hasil Data Training Hoax Lebih Banyak

Bertambahnya jumlah data training mengakibatkan nilai probabilitas kelas pada sistem menjadi tidak seimbang. Hasil klasifikasi berubah dari yang sebelumnya fakta menjadi hoax, dikarenakan data training hoax lebih banyak daripada data training fakta. Oleh karena itu masing-masing kelas dari data training harus mempunyai data yang seimbang.

\section{B. Analisis Kelas Netral}

Apabila jumlah data training tidak seimbang maka hasil klasifikasi akan mengikuti jumlah data training terbanyak. Pada tahap analisis ini, akan dilakukan pengujian, apakah data netral akan berpengaruh apabila jumlah data training tidak seimbang. Gambar 4 menunjukkan hasil klasifikasi netral setelah ditambahkan 1 data training hoax.

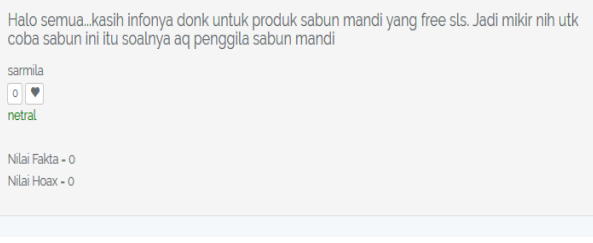

Gambar 4. Hasil Pengujian Kelas Netral

Pada Gambar 4 dapat disimpulkan bahwa penambahan jumlah data training yang tidak seimbang tidak memengaruhi hasil klasifikasi netral. Selama kata pada netral tidak ada pada data training fakta ataupun hoax. Kemudian klasifikasi netral dapat terjadi apabila nilai fakta dan hoax bernilai 0 .
C. Analisis Fakta dan Hoax Mempunyai Nilai yang sama

Tahap ini, membahas apabila nilai fakta dan hoax mempunyai nilai yang sama

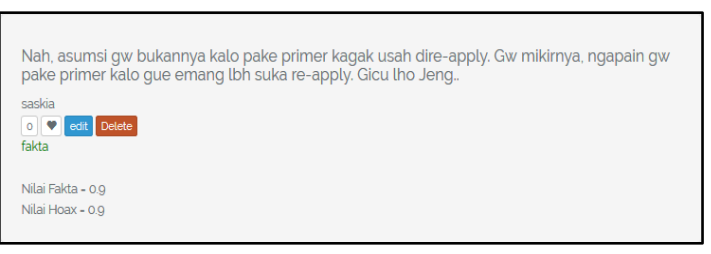

Gambar 5. Hasil Nilai yang Sama

Pada Gambar 5 komentar mempunyai hasil fakta dan hoax yang sama. Hal ini disebabkan karena pada komentar tersebut terdapat 1 kata fakta dan 1 kata hoax. Yaitu "asumsi" untuk kata hoax dan "suka" untuk kata fakta. Kemudian alasan mengapa data tersebut diklasifikasikan sebagai fakta karena rumus pada kode sistem adalah 'if (\$bodyTextIsFakta $>=$ \$bodyTextIsHoax)'. Yang berarti jika fakta lebih besar sama dengan hoax. Maka dari itu, apabila fakta dan hoax mempunyai jumlah yang sama maka hasil klasifikasi adalah fakta.

\section{Accuracy Naive Bayes Clasification for Filtering Hoax}

Hasil dari uji coba dari 50 data testing dengan website forum Female Daily untuk hoax, netral atau fakta data testing yang dikumpulkan dari 6 Febuari 2015 s/d 7 Juni 2018. Berikut di bawah ini adalah perhitungan Confusion Matrix untuk menghitung akurasi algoritma peroleh nilai:

1. $\mathrm{TP}=42$ dari 50 komentar berhasil diklasifikasi dengan sukses.

2. $\mathrm{TN}=2$ dari 50 komentar berhasil diklasifikasi tapi tidak meyakinkan.

3. FP $=6$ dari 150 komentar berhasil diklasifikasi tetapi, gagal.

4. $\mathrm{FN}=0$ dari 150 komentar tidak berhasil diklasifikasi dan gagal.

Berikut di bawah ini adalah perhitungan akurasi dari sistem tersebut.

$$
\text { Accuracy }=\frac{42+2}{42+2+6+0} \times 100 \%=\frac{44}{50}=88 \%
$$

Dari hasil perhitungan akurasi dengan menggunakan rumus di atas, dapat disimpulkan hasil akurasi dari sistem tersebut adalah 88\% dengan menggunakan Nä̈ve Bayes Classifier. 


\section{KESIMPULAN DAN SARAN}

Sistem forum yang dirancang adalah filtering hoax pada komentar di dalam Forum Female Daily digunakan untuk menyaring kata hoax yang ada pada komentar. Hasil akurasi pengujian data testing filtering hoax dengan menggunakan algoritma Naïve Bayes Classifier adalah $88 \%$ yang diambil dari 50 data testing komentar pada forum Female Daily. Data testing komentar yang diambil berkisar dari 6 Febuari 2015 s/d 7 Juni 2018. Keakuratan yang didapat tergantung dari data training serta proses text preprocessing. Sistem ini masih mempunyai banyak kekurangan yaitu:

1. Perlu penambahan fitur.

2. Perlu penambahan data set untuk mendapatkan hasil klasifikasi dengan akurasi yang lebih baik.

3. Menambahkan fitur web crawler agar data semakin banyak dan dapat mem-filter lebih banyak kategori.

\section{REFERENSI}

[1] Budi, D. S., Siswa, T. A., \& Abijono, H. (2016). Analisis Pemilihan Penerapan Proyek Metodologi Pengembangan Rekayasa Perangkat Lunak. Teknika, 24-31.

[2] M. Granik and V. Mesyura, "Fake News Detection Using Naive Bayes Classifier," IEEE First Ukraine Conference on Electrical and Computer Engineering (UKRCON), pp. 900-903, 2017.

[3] Informatikalogi, "Informatikalogi.com," 27 November 2017. [Online]. Available: https://informatikalogi.com/ text-preprocessing/. [Accessed 29 Mei 2018].

[4] Aida, I. (2014). Klasifikasi Data Forum dengan Menggunakan Metode Naïve Bayes Classifier. Seminar Nasional Aplikasi Teknologi Informasi (Snati), 5-10.

[5] Trinanda, R. P. (2014). Penggunaan Metode Naïve Bayes Classifier pada Aplikasi Perpustakaan. Jurnal Teknologi Dan Informasi Unikom, 1-7.

[6] Mahmudy, W. F., \& Widodo, A. W. (2014). Klaisifikasi Artikel Berita Secara Otomatis Menggunakan Metode Naive Bayes Classifier yang Dimodifikasi. Tekno, 21. 